\title{
Long-Term Changes of Heavy Precipitation and Dry Weather in Japan (1901-2004)
}

\author{
Fumiaki FUJIBE, Nobuo YAMAZAKI ${ }^{1}$ \\ Meteorological Research Institute, Tsukuba, Japan \\ and \\ Kenji KOBAYASHI \\ Observations Department, Japan Meteorological Agency, Tokyo, Japan
}

(Manuscript received 2 June 2006, in final form 7 September 2006)

\begin{abstract}
Long-term changes in the intensity and frequency of heavy precipitation in Japan were analyzed using quality checked daily precipitation data at 51 stations from 1901 to 2004 . The analysis is based on ten categories defined from precipitation intensity and frequency, and some indices of heavy precipitation, such as $\geq 100 \mathrm{~mm}$ days, the annual maximum, and the top 100 cases during the 104 years. The result indicates that heavy precipitation based on these indices has increased during the 104 years. The linear trend of precipitation corresponding to the upper $10 \%$ is $2.3 \%$ per decade, and that of the number of top 100 cases is $2.6 \%$ per decade on the average over the stations. The increase is most pronounced in western Japan and in autumn, while weak, but similar signals are found in other regions and seasons as well. However, no increasing trend is found for less intense precipitation, such as $\geq 50 \mathrm{~mm}$ days and the number of top 1000 cases.

Analysis was also made for 5, 11, and 31 day precipitations, and some indices of dry weather. It is found that the frequency of dry weather has increased during the 104 years. The number of days with precipitation less than $1 \mathrm{~mm}$ has increased in all the seasons and regions, with a trend of $0.4-0.7 \%$ per decade on the average, while the lower $1 \%$ of cases of 31-day precipitation have doubled with a trend of $10 \%$ per decade.
\end{abstract}

\section{Introduction}

The long-term change of extreme weather events is an important aspect of the climatic change. It has been found in many regions of the world that heavy precipitation has increased on the time scale of several decades to a century (IPCC 2001; Karl and Knight 1998;

Corresponding author: Fumiaki Fujibe, Meteorological Research Institute, 1-1 Nagamine, Tsukuba 305-0052, Japan.

E-mail: ffujibe@mri-jma.go.jp

1 Present affiliation: Meteorological College, Kashiwa 277-0852, Japan.

(C) 2006, Meteorological Society of Japan
Easterling et al. 2000; New et al. 2001; Groisman et al. 2005). A number of AGCM simulations have predicted precipitation to be heavier, with shorter duration as the progress of global warming (e.g., Hegerl et al. 2004; Kimoto et al. 2005). There are some regional and/or seasonal differences in the sign and magnitude of the change (Haylock and Nicholls 2000; Roy and Balling 2004; Wang and Zhou 2005; Semenov and Bengtsson 2002; Kitoh et al. 2004; Wehner 2004), as well as the dependence on time of the day (Dai 1999; Fujibe et al. 2006).

The change in the number of rainy days, and dry days, is another interesting problem from 
the viewpoint of agriculture and water resource management. The number of rainy days has increased by $6 \%$ during the 20 th century in the contiguous United States (Karl and Knight 1998), while a decreasing trend is found in some regions including part of East Asia, in spite of the increase of heavy precipitation (Brunetti et al. 2004; Zhai et al. 2005). The trend of annual maximum consecutive dry days (CDD), which is an index of duration of dry weather, shows a complicated regional pattern, with a slight decrease on the global average (Frich et al. 2002; Alexander et al. 2006).

A difficulty in detecting the changes in extreme precipitation is the lack of data having a sufficient time resolution with a long span (New et al. 2001; Groisman et al. 2005; Alexander et al. 2006). In Japan, several tens of stations have precipitation data for over a hundred years. Using these data, annual precipitation in Japan has been found to have a slight decreasing trend during the last century (JMA 2005). Iwashima and Yamamoto (1993) showed that more stations recorded the highest, second highest or third highest values of daily precipitation in the most recent decades. However, daily and hourly data were available on digital media for only a limited period (since 1961), while data prior to 1960 were stored in microfilms. Some researchers analyzed the increase of heavy precipitation for the last 50100 years using the microfilm data (Kajiwara et al. 2003; Takahashi 2003; Kanae et al. 2004; Suzuki 2004), but the major part of the data before 1960 have remained unused in spite of their high reliability and nearly complete time coverage.

During the last few years, precipitation data at stations of the Japan Meteorological Agency (JMA) were digitalized for the full period of operation, which started before 1900 at some stations. Using this dataset, Fujibe et al. (2005) analyzed the trends of daily, four-hourly and hourly precipitations for the period 1898-2003 on the basis of ten intensity categories of precipitation intensity. They showed the increase of heavy precipitation at a rate of $20-30 \%$ per century for all of the three time intervals. They also showed the decrease of weak precipitation, implying the increase of dry periods. However, the data used for their analysis had many missing and doubtful records arising from errors in the digitalization process. Although a rough check was done, the data quality was insufficient to obtain the long-term trend of extreme precipitation.

Recently, a quality check for the daily precipitation data from 1901 at 51 stations was made in the Observations Department of the JMA. The resulting dataset provides complete daily records with only a few missing values (see Section 2.1 for details). In the present study, the long-term trends in high and low extremes of precipitation in Japan were described using this dataset. Not only daily values, but also 5day, 11-day and 31-day precipitations are analyzed in order to find the changes of heavy precipitation, and dry weather defined on the time scale from a day to a month.

As remarked by New et al. (2001), "most studies have differing definitions of intense precipitation, which makes comparison of results problematic". In fact, some indices are highly inhomogeneous in space and time of the year. For example, the number of daily precipitation events exceeding some values (say, $100 \mathrm{~mm}$ ) is simple and clear-cut, but it represents only a limited area and season, as shown in the next section (Figs. 4 and 5). On the other hand, some indices having high homogeniety over regions and seasons may be less easily understandable. We therefore deal with various indices in order to have a wide view of the long-term changes of heavy precipitation, and dry weather in Japan. First, the relationship between the precipitation trends and intensity is described on the basis of categories defined in a similar way to that of Fujibe et al. (2005). Then, further analysis for some indices of heavy precipitation and dry weather is presented.

\section{Data and preliminary analysis}

\subsection{Data}

The analysis is based on daily precipitation data at 51 stations (Fig. 1) for the period from 1901 to 2004 . Among these stations, 11 are located in northern Japan (Hokkaido and Tohoku districts), 18 are in eastern Japan (Kanto and Chubu districts, including Mie prefecture), 19 are in western Japan (Kinki, Chugoku, Shikoku, and Kyushu districts), and three are on the Nansei Islands. Table 1 shows the stations where more than three missing records are found in a month. Data for nearly seven years 


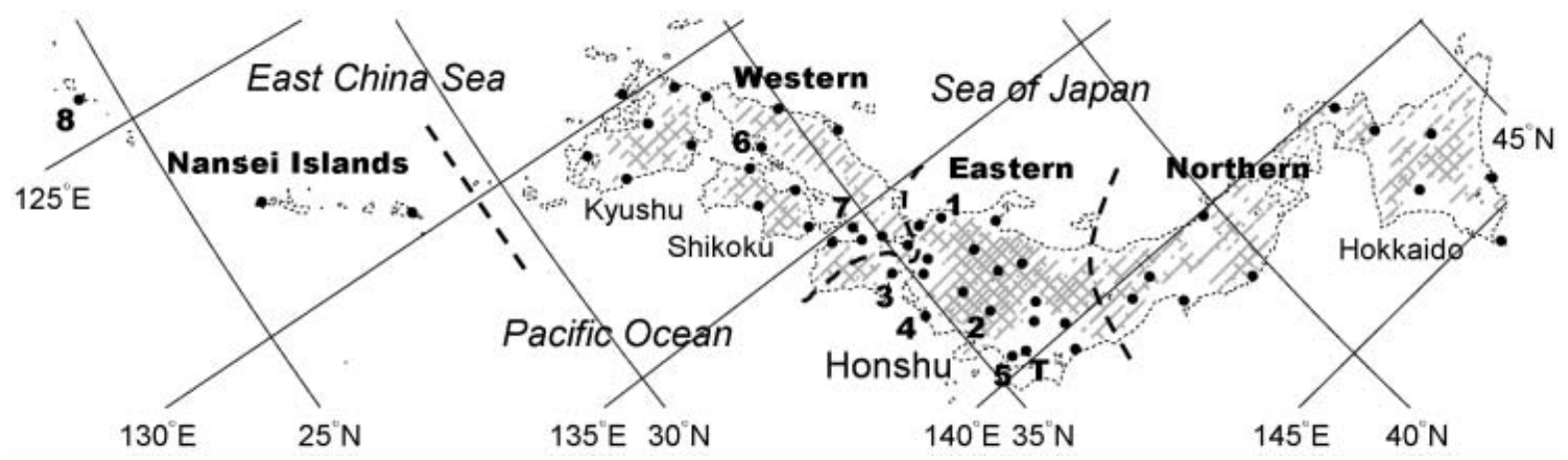

Fig. 1. Location of the 51 stations. Symbols 1-8 indicate the stations listed in Table 1, and T indicates Tokyo. Hatching shows the area above $300 \mathrm{~m}, 600 \mathrm{~m}$ and $1200 \mathrm{~m}$ from the mean sea level with increasing tones.

Table 1. List of stations with more than ten missing records.

\begin{tabular}{|c|c|c|c|}
\hline \multicolumn{2}{|c|}{ Station } & \multirow{2}{*}{$\begin{array}{l}\text { Periods of missing data }{ }^{1)} \\
\text { Feb.-Dec. 1938 (except May, July and Oct.); } \\
\text { June 1941; July-Aug. } 1945\end{array}$} & \multirow{2}{*}{$\frac{\text { Number of months }^{1)}}{11}$} \\
\hline 1 & Fukui & & \\
\hline 2 & Kofu & June-July 1945 & 2 \\
\hline 3 & Tsu & July 1989 & 1 \\
\hline 4 & Hamamatsu & June 1945 & 1 \\
\hline 5 & Yokohama & Aug.-Dec. 1923 & 5 \\
\hline 6 & Kure & Apr. 1945; June 1945-Sep. 1946 & 17 \\
\hline 7 & Kobe & Mar. 1945 & 1 \\
\hline 8 & Naha & $\begin{array}{l}\text { Jan.-July 1923; May 1924; Oct. 1943; Sep. 1944; } \\
\text { Feb. 1945-Dec. 1950; Feb.-Mar. } 1951\end{array}$ & 83 \\
\hline
\end{tabular}

${ }^{1)}$ More than three missing records in a month.

are lacking at Naha, but blank periods are much shorter at other stations. Except for the stations listed here, the data coverage is nearly perfect with missing records less than ten during the 104 years, namely 37986 days.

Precipitations for consecutive 5, 11, and 31 days were obtained by the running sum of daily values. They were left undefined for the beginning and end of the analysis period, namely January 1901 and December 2004, for which it was impossible to obtain running sums.

The precipitation observation in Japan was made with the conventional cylinder-type raingauge, with resolution of $0.1 \mathrm{~mm}$ until 1967 . Since 1968, the tipping bucket raingauge has been used with resolution of $0.5 \mathrm{~mm}$. In this study, all the data were reduced to the resolution of $0.5 \mathrm{~mm}$ in order to avoid the bias due to the difference in observation resolution. The tipping bucket raingauge incrementally mea- sures the precipitation accumulation, so that precipitation of $1.2 \mathrm{~mm}$, for example, will be measured to be $1.0 \mathrm{~mm}$ at the $60 \%$ probability, and $1.5 \mathrm{~mm}$ at the $40 \%$ probability, depending on the initial water contained in the bucket. Reduction to the $0.5 \mathrm{~mm}$ resolution was made by applying these probabilities as weights to the neighboring half-integer values. For example, a record of $1.2 \mathrm{~mm}$ was treated as a $1.0 \mathrm{~mm}$ record with a weight of 0.6 and a $1.5 \mathrm{~mm}$ record with a weight of 0.4 .

The above-mentioned procedure does not take into account the evaporation in the tippingbucket raingauge. Unlike the cylinder-type one, the observation with the tipping-bucket raingauge does not receive a daily check, so that the water remaining in the bucket may be lost by evaporation before the next precipitation. Unfortunately, it is impossible to make an accurate evaluation of this effect. Instead, we at- 
tempt a rough estimation by considering an extreme case in which remaining water is totally lost by the next day. This case corresponds to truncating the fraction below $0.5 \mathrm{~mm}$ in converting the cylinder-type data to the tippingbucket data. Hereafter we call it the "total evaporation" case, as opposing to the "no evaporation" assumption described in the previous paragraph. The following analysis is based on the no evaporation assumption, but the results obtained from the total evaporation assumption are occasionally presented for comparison.

There are also some problems of undercatch due to turbulence around the raingauge, raindrop splashing and wetting, which may depend on the type of raingauges and cause temporal inhomogeniety (New et al. 2001; Groisman et al. 2005). However, these problems are difficult to evaluate, and are not considered in this study.

\subsection{Indices of extreme precipitation and dry days}

Fujibe et al. (2005) defined ten intensity categories of precipitation so as to equate the total precipitation amount, for each station and each month. The same procedure was used in the this study. For example, a tenth of the rainfall amount at Tokyo in August $(159.2 \mathrm{~mm}$ ) is contributed by daily precipitation less than $7.6 \mathrm{~mm}$, another tenth by $7.6-14.7 \mathrm{~mm}$, and the last tenth by precipitation more than $144.9 \mathrm{~mm}$ (Fig. 2). Hereafter, the upper bound of the lowest category is denoted by the " $10 \%$ point", and the lower bound of the highest category by the "90\% point". In a similar way, categories for 5, 11, and 31-day precipitations were defined.

Categorization in frequency was made as well. For example, $10 \%$ of the days in August at Tokyo correspond to 31-day precipitation (running sum) of $30.7 \mathrm{~mm}$ or less, while the other $10 \%$ corresponds to $324.3 \mathrm{~mm}$ or more. Thus, the $10 \%$ and $90 \%$ points in the frequency of 31-day precipitation are $30.7 \mathrm{~mm}$ and $324.3 \mathrm{~mm}$, respectively. Naturally the categories in frequency correspond to smaller threshold values than those defined from the amount, for which the $10 \%$ and $90 \%$ points for August at Tokyo are $84.9 \mathrm{~mm}$ and $399.7 \mathrm{~mm}$, respectively.

The analysis of heavy precipitation is based

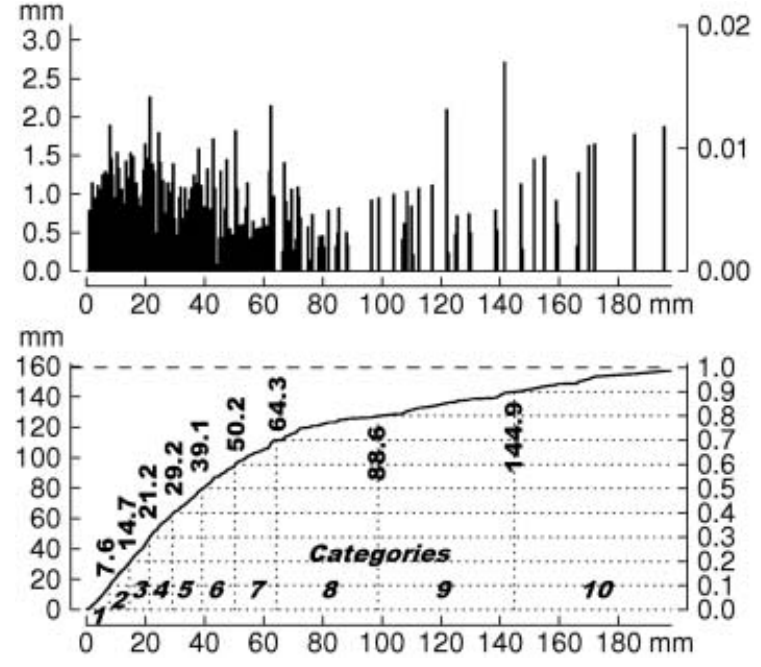

Fig. 2. Definition of intensity categories, for daily precipitation at Tokyo in August as an example. The upper panel shows the precipitation amount per month for each $0.5 \mathrm{~mm}$ interval (average for 1901-2004), and the lower panel shows its integration, namely the cumulative precipitation amount. In both panels, scales on the left give precipitation amount, and those on the right indicate relative amount with respect to the total.

on three kinds of indices. The first is the number of days on which precipitation amount was, or exceeded, a given threshold. The value of $100 \mathrm{~mm}$ is used as representing heavy precipitation. For the sake of comparison, $20 \mathrm{~mm}$ and $50 \mathrm{~mm}$ are used as representing less intense precipitation. It is to be noted that daily precipitation of $10 \mathrm{~mm}$, which is often used as an index of "heavy precipitation" (e.g., Alexander et al. 2006), is too low for Japan, where $\geq 10 \mathrm{~mm}$ precipitation occurs on more than 80 days per year at some stations. The second index is the maximum precipitation in each year (annual max). Analysis was also made for the maximum in a ten-year period (decadal max), and the tenth highest precipitation in a year (annual tenth) as indices of very intense, and less intense precipitation. The third index is the frequency of the upper 10, 100, and 1000 cases of precipitation during the 104 years (top 10, 100, and 1000), corresponding to the upper $0.0263 \%, 0.263 \%$, and $2.63 \%$ of the total cases 

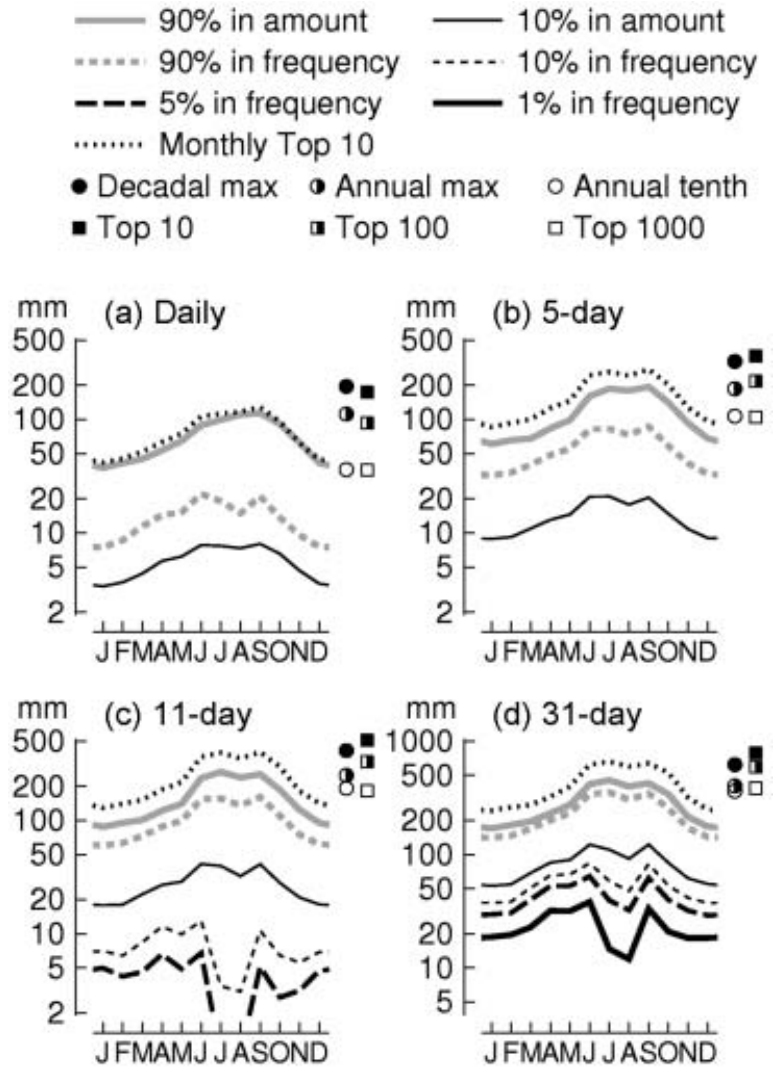

Fig. 3. Precipitation values corresponding to the indices used for analysis, averaged over the stations.

(37986 days), respectively. The upper 10 cases for each month (monthly top 10) were also analyzed in order to examine the seasonal characteristics. The annual maximum and the top 100 cases were defined not only for daily precipitation, but also for 5, 11, and 31-day precipitations.

The analysis of dry weather is based on (1) the number of $<1 \mathrm{~mm}$ days and $<30 \mathrm{~mm} /(31$ days) cases, which include no precipitation cases, and (2) the number of lower 10\%, 5\% and $1 \%$ cases of 11 , and 31-day precipitations. The lower $10 \%$ is nothing other than the lowest category (category 1) in frequency.

Figure 3 shows the monthly values of precipitation corresponding to the above-mentioned categories and indices, averaged over the 51 stations and the 104 years. The 10\%-1\% points in frequency are not shown for daily and 5-day precipitations, because they are zero or nearly

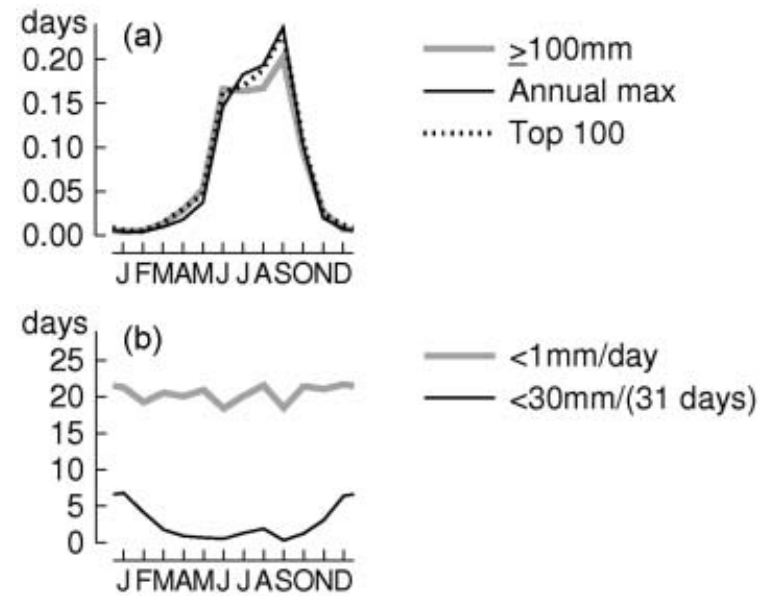

Fig. 4. Number of days (per year per station) corresponding to each index.

zero. We can see that (1) the $90 \%$ point and the monthly top 10 precipitation are more than twice larger in summer than in winter; (2) the $90 \%$ point in amount is nearly an order of magnitude larger than that in frequency for daily precipitation, but the difference decreases toward a longer time scale; and (3) the monthly top 10 precipitation is some tens of percent larger than the $90 \%$ point in amount. Figure 3 also shows the values of the decadal maximum, annual maximum and tenth, as well as the top 10th, 100th, and 1000th cases. As expected, there is rough agreement between the decadal maximum and the top 10th, the annual maximum and the top 100th, and the annual tenth and the top 1000th, respectively.

Figure 4a shows the monthly number of $\geq 100 \mathrm{~mm}$ days, and the number of days on which annual maximum precipitation and the top 100 cases were observed. Most of the cases occur from June to October. Thus these indices represent the climatology of heavy precipitation in the warm season. Figure $4 \mathrm{~b}$ shows the annual variation of $<1 \mathrm{~mm}$ days, and $<30 \mathrm{~mm} /$ (31 days) cases. The $<1 \mathrm{~mm}$ days are uniformly distributed throughout the year, apart from regional features which vary according to seasons. The $<30 \mathrm{~mm} /(31$ days $)$ cases have higher frequency in winter than in summer, with a secondary maximum in August. The high frequency in winter is explained by the small moisture content in the atmosphere, and also by the orographic rain shadow in the north- 
(a) $\geq 100 \mathrm{~mm}$ days

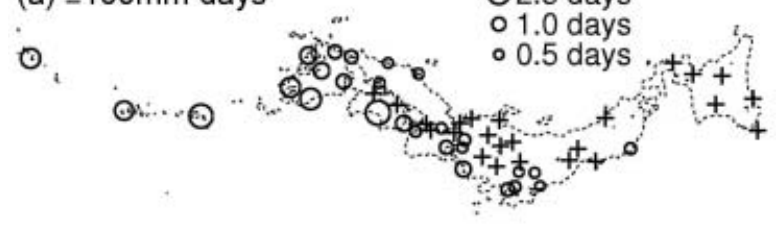

(b) Annual max.

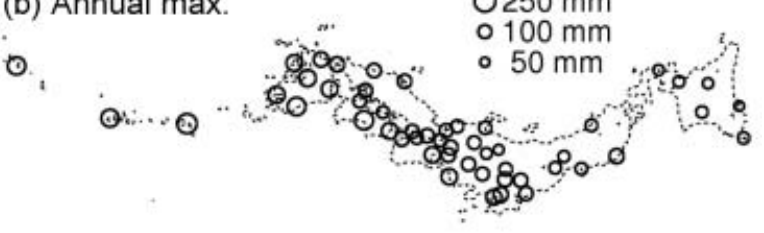

(c) $<30 \mathrm{~mm} /(31$ days)

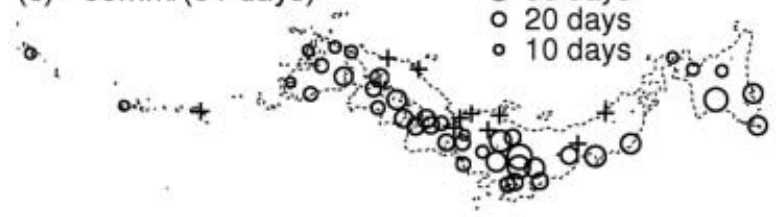

Fig. 5. Distribution of each index averaged over the 104 years. Crosses indicate values less than the smallest value in each legend $(<0.5$ day for (a), for example).

western monsoon on the southeastern side of the Japanese Islands. The weak maximum in August corresponds to a midsummer dry period, in which hot and sunny weather prevail under the subtropical high, although heavy precipitation sometimes occurs due to tropical storms and/or frontal systems.

There are also regional differences in the precipitation amount or frequency. The 90\% and $10 \%$ points differ according to stations by a factor of two or more (not shown). Figure $5 a-b$ shows the distribution of the number of $\geq 100 \mathrm{~mm}$ days, and the annual maximum daily precipitation. The number of $\geq 100 \mathrm{~mm}$ days has a highly uneven distribution with a few days per year on the southern coast of western Japan, and the Nansei Islands, and less than 0.1 days in part of northern Japan. The annual maximum precipitation is less inhomogeneous, but there is still a regional difference of a factor of three. Figure 5c shows the number of $<30 \mathrm{~mm}$ cases in the 31-day precipitation, as an index of dry weather on a monthly scale. The number of days is larger on the southeastern side of the land, corresponding to the rain shadow in winter mentioned in the previous paragraph. On the other hand, there is no regional difference in the number of top 10-1000 cases, and the lower $1-10 \%$ cases.

\subsection{Calculation of linear trends}

The regional and annual (or seasonal) average of precipitation in the category $r$ was obtained by

$$
P_{n r}=\sum_{i, m} p_{n m i r} / N_{n}
$$

where $p_{\text {nmir }}$ is the precipitation amount in category $r$ at station $i$ in the month $m$ in year $n$, and $N_{n}$ is the number of months in the summation. If there were more than three missing records in a month, then $p_{\text {nmir }}$ was left undefined and excluded from the summation. The linear trend of $P_{n r}$ was calculated from the least-squares condition

$$
\begin{aligned}
\sum_{n}[ & \left.P_{n r}-\left\{a_{r}+b_{r}\left(n-\frac{n_{1}+n_{2}}{2}\right)\right\}\right]^{2} \\
& \rightarrow \text { min. }
\end{aligned}
$$

where $n_{1}$ and $n_{2}$ are the first and the last year of the analysis period (namely, 1901 and 2004), and $a_{r}$ and $b_{r}$ are the least-squares coefficients indicating the long-term mean and the trend, respectively. Hereafter, we use suffices if there is need to specify the way of categorization and precipitation duration. For example, $b_{a, 10}^{(1)}$ indicates the trend for the category 10 , based on categorization in daily precipitation amount, while $b_{f .1}^{(31)}$ indicates that for the category 1 , obtained from categorization in the frequency of 31-day precipitation. The same procedure was applied to calculate the linear trend of other indices.

\section{Precipitation trends for the categories}

Figure 6 shows the time series of annual precipitation amount averaged over the stations. In addition to the large year-to-year fluctuation, there is a linear trend of $-0.56 \%$ per decade, with the $95 \%$ confidence range of $0.65 \%$ per decade (hereafter denoted as $-0.56 \pm 0.65 \%$ / decade). Thus precipitation amount in Japan has a slight decreasing trend, unlike the increasing tendency on the global scale (IPCC 2001; Alexander et al. 2006). Figure 6 also shows the time series of four-year average precipitation. The short-term fluctuation is greatly 


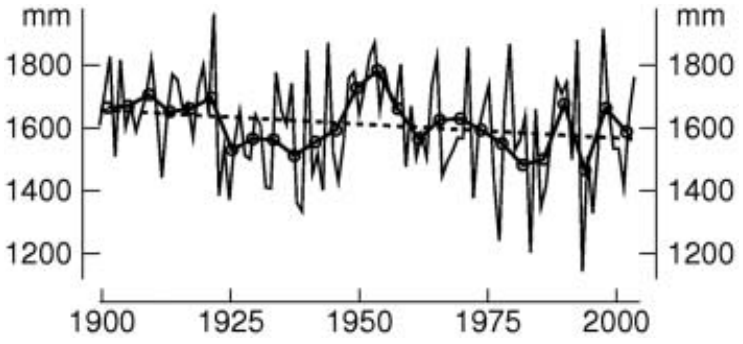

Fig. 6. Time series of annual precipitation averaged over the stations. In this figure and Fig. 11, the thick line with dots indicates the average of each four years, and the dotted line indicates the linear regression.

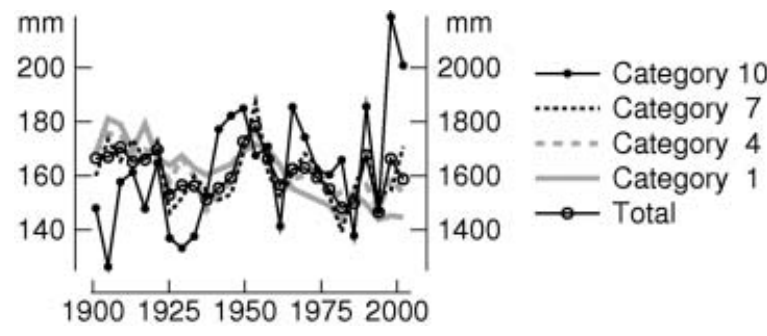

Fig. 7. Time series of precipitation for categories 1, 4, 7 and 10 (left scale) and the total precipitation (right scale). In this and the following figures of the same style, averages over the stations for each four years are shown with a linear regression line. The graph of the total precipitation is the same as that shown in Fig. 6.

reduced, and replaced by a long-term variation characterized by a wet period around 1950, and dry periods around 1930 and 1980, as well as the weak decreasing trend. The four-year average is therefore more suitable for observing the long-term change.

Figure 7 shows the time series (four-year average) of $P_{n r}$ for $r=1,4,7$, and 10 of the daily precipitation averaged over the stations. The highest category $(r=10)$ shows an increasing trend, while the lowest category $(r=1)$ has a distinct decreasing trend, although short-term variations are considerably large. Hereafter we focus on the linear trend $\left(b_{a}\right.$ and $b_{f}$ defined in (2)), keeping in mind the existence of interannual variations.

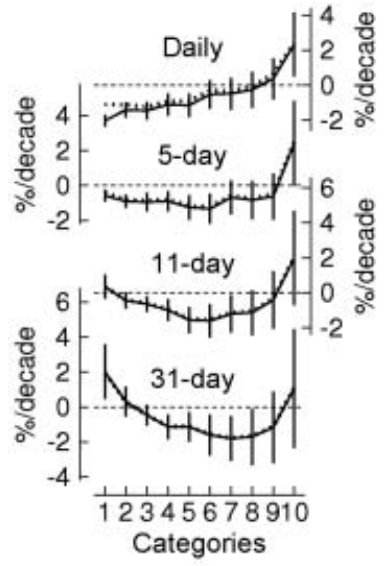

(a) $b a$

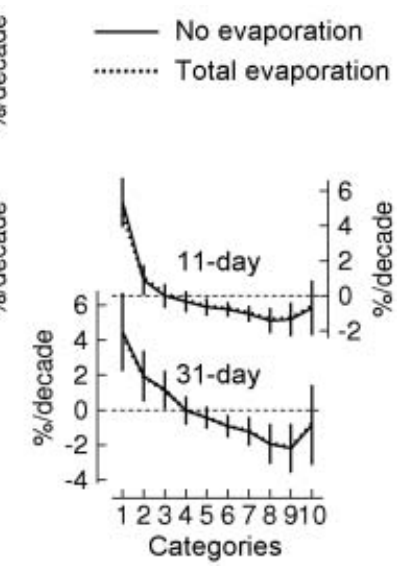

(b) bf
Fig. 8. Linear trend of precipitation in each category defined from (a) precipitation amount and (b) frequency. Vertical bars show the 95\% confidence range. Dotted lines indicate the results obtained from the total evaporation assumption.

Figure 8a shows $b_{a}$ as a function of $r$ averaged over the stations. The results based on the "no evaporation", and the "total evaporation" assumptions, are both presented. For daily precipitation, there is an increasing trend in the highest category, and a decreasing trend in lower categories irrespectively of the assumptions. The values of $b_{a, 10}^{(1)}$ and $b_{a, 1}^{(1)}$, namely the trends of the highest and lowest categories, are $\pm 2 \%$ /decade according to the no evaporation assumption (Table 2 ). If the total evaporation assumption is used, $b_{a, 1}$ is halved, but $b_{a, 10}$ is almost unchanged (Table 2). Thus the assumption on the evaporation in raingauges substantially affects the trend of weak precipitation, but does not alter the qualitative features of the change.

The values of $b_{a, 10}$ are positive for 5 - and 11day precipitations as well, although they are smaller than that of daily precipitation. For 11 and 31-day precipitations, $b_{a, 1}$ is also positive so that the $b_{a}$ graph has a "U" shape. The evaporation in raingauges has little effect for duration of 5 days and up.

Figure $8 \mathrm{~b}$ shows the values of $b_{f}$ for $11-$ and 31-day precipitations (results for daily and 5day precipitations are not shown, because $b_{f}$ are undefined for some categories correspond- 
Table 2. Linear trends (\%/decade) for some categories.

\begin{tabular}{ccccccc}
\hline \hline & Whole area & Northern $^{\#}$ & Eastern $^{\#}$ & Western $^{\#}$ & $\begin{array}{c}\text { Nansei } \\
\text { Islands }^{\#}\end{array}$ & $\begin{array}{c}\text { Whole area } \\
\text { (total evap.) }\end{array}$ \\
\hline Number of stations & 51 & 11 & 18 & 19 & 3 & 51 \\
$b_{a, 1}^{(1)}$ & $-2.02 \pm 0.34$ & $-2.05 \pm 0.41$ & $-1.80 \pm 0.45$ & $-2.01 \pm 0.49$ & $-2.92 \pm 0.58$ & $-1.10 \pm 0.33$ \\
$b_{a, 10}^{(1)}$ & $2.34 \pm 1.83$ & $1.28 \pm 2.55$ & $1.10 \pm 2.18$ & $4.28 \pm 2.62$ & $0.47 \pm 3.40$ & $2.39 \pm 1.83$ \\
$b_{f, 1}^{(31) \$}$ & $4.46 \pm 2.23$ & $3.01 \pm 2.46$ & $5.65 \pm 2.89$ & $3.91 \pm 2.99$ & $6.16 \pm 3.75$ & $4.30 \pm 2.23$ \\
$b_{f, 10}^{(31)}$ & $-0.85 \pm 2.27$ & $-2.04 \pm 2.72$ & $-1.51 \pm 2.83$ & $0.52 \pm 2.95$ & $-1.25 \pm 3.70$ & $-0.79 \pm 2.27$ \\
\hline
\end{tabular}

\# See Fig. 1 for definition.

\$ Same as the trend of lower $10 \%$ cases discussed in Section 4.

ing to no precipitation cases). There is conspicuous increase for the lowest category with a $b_{f, 1}$ value of $4-5 \% /$ decade (Table 2 ). On the other hand, frequencies of high categories have negative trends, although the highest category shows a slight upward shift from the lower category.

The values of $b_{a, 1}^{(1)}, b_{a, 10}^{(1)}, b_{f, 1}^{(31)}$ and $b_{f, 10}^{(31)}$ for the four regions (Fig. 1) are shown in Table 2. Each of the former three items has the same sign over the regions. The values of $b_{a, 10}^{(1)}$ has considerable regional differences, with a much larger value in western Japan than in other regions, but the confidence ranges are too large to judge the statistical significance of the difference. In this respect, the statistically significant increase of the whole-area average deserves to be stressed rather than the regional differences.

Figure 9a shows $b_{a}^{(1)}$ for the four seasons. The value of $b_{a, 10}$ is largest in autumn, and much smaller in winter and spring. Nevertheless, there is qualitative agreement among seasons with respect to positive inclination of the graph, indicating the relative increase of heavy precipitation. Figure 10 shows the distribution of $b_{a, 10}^{(1)}$, evaluated for each station. Positive trends are found in many stations in western Honshu, Shikoku and Kyushu (hereafter denoted by "western Japan") throughout the year. In central Honshu, $b_{a, 10}^{(1)}$ has large positive values in autumn, but is strongly negative in spring and summer in the inland region. In winter, $b_{a, 10}^{(1)}$ is positive at many stations on the southeastern side of central Honshu, and negative at some stations on its northwestern side. On the annual average, trends are only slightly positive in central Honshu, and also from northern

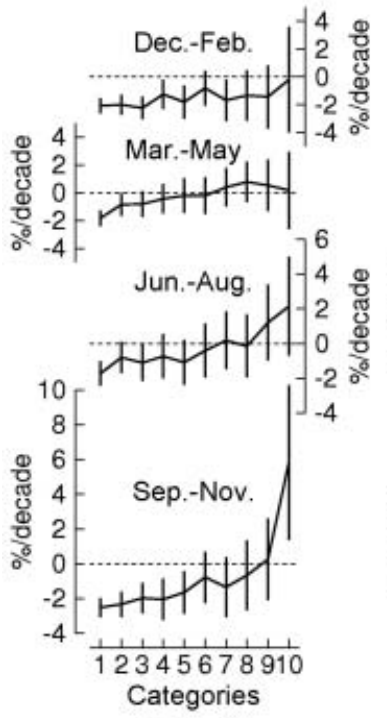

(a) $b_{a}^{(1)}$

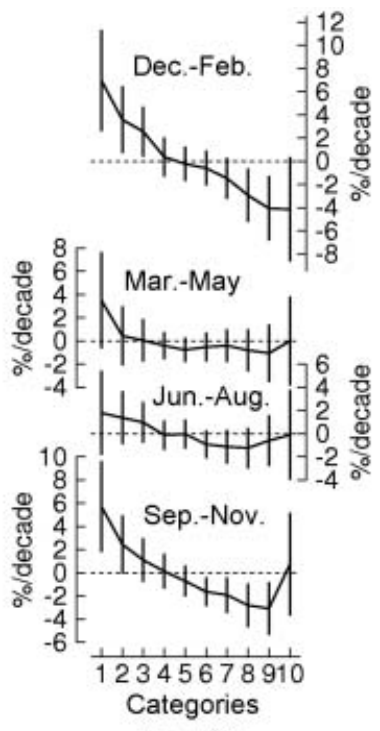

(b) $b f^{(31)}$
Fig. 9. Linear trend of (a) daily precipitation categorized in amount, and (b) 31-day precipitation categorized in frequency, for each season.

Honshu to Hokkaido, and over the Nansei Islands. These regional and seasonal features can be found for other durations (not shown), with only some minor differences. As discussed in the previous paragraph, the statistical significance of regional differences are open to further analysis.

Figure $9 \mathrm{~b}$ shows the trend defined from the frequency of 31-day precipitation, $b_{f}^{(31)}$, for the four seasons. The low categories commonly show a positive trend which is most conspicuous in winter. However, the trend of the high- 


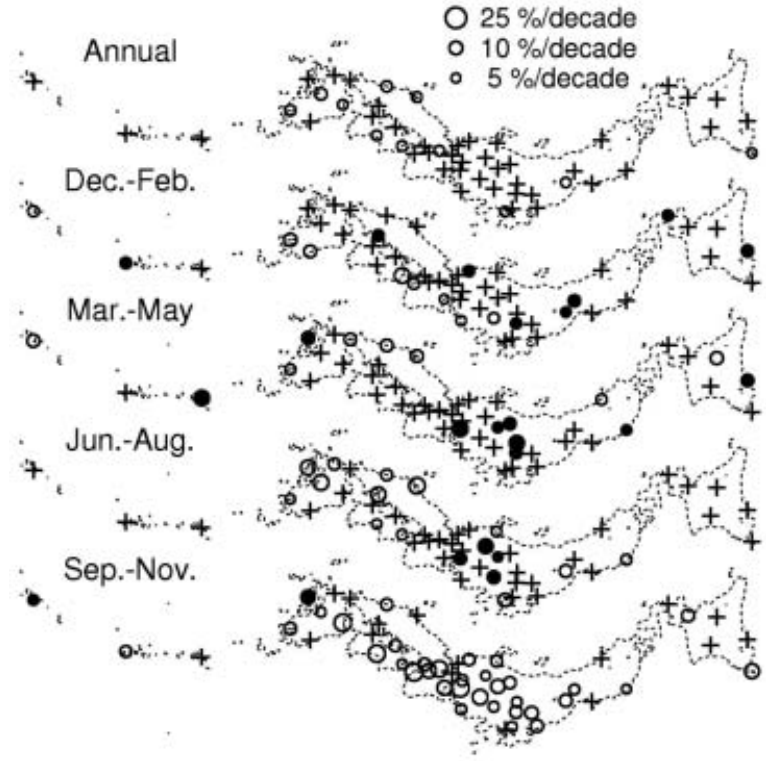

Fig. 10. Distribution of $b_{a, 10}^{(1)}$, namely the linear trend of the highest category in daily precipitation. Open and closed circles indicate positive and negative values, respectively. Crosses indicate values less than $5 \% /$ decade.

est category is very weak or negative. More details of the change in dry days, and dry weather, are presented in section 5 .

\section{Trends of heavy precipitation indices}

Analysis of extreme precipitation indices was made in the same way as applied for precipitation categories, with $p_{\text {nmir }}$ in Eq. (1) substituted by each index defined in section 2. Figure 11a shows the time series of the number of $\geq 100 \mathrm{~mm}$ days averaged over the stations. Figure $11 \mathrm{~b}-\mathrm{c}$ show the annual maximum, and the number of top 100 cases of daily precipitation. Although the three indices differ in the degree of spatial unevenness (Fig. 5), they commonly show increasing trends, which are significant at the 5\% level (Table 3), in addition to considerable interannual variations. The value of the trend is $0.9 \% /$ decade for the annual maximum precipitation, and about $2.5 \% /$ decade for the other two indices. The smaller trend of the annual maximum than the other two reflects the lower sensitivity of precipitation amount to climatic change than frequency.

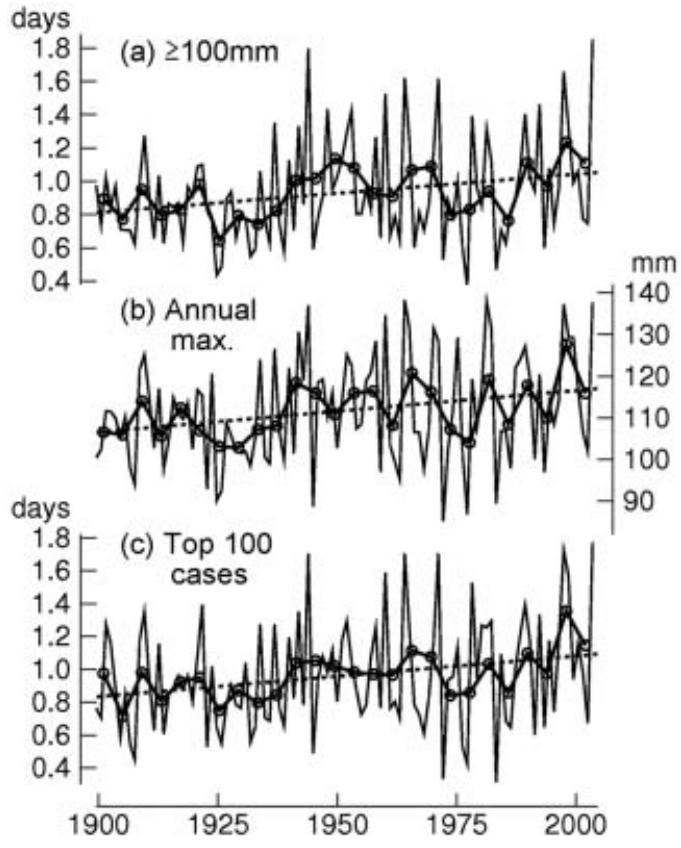

Fig. 11. Time series of $\geq 100 \mathrm{~mm}$ days, annual maximum precipitation, and the frequency of the top 100 cases of daily precipitation.

Figure 12 shows the distribution of the trend at each station. The majority of the stations show positive trends, except negative trends at some stations from central to northern Honshu, and in Hokkaido. Table 3 shows the value of the trend for each region. There are positive trends in all the regions. Although trends are much higher in the western region than in other regions (except the $\geq 100 \mathrm{~mm}$ days in northern Japan), the large confidence ranges again hinder a definite conclusion about regional differences.

Figure 13 shows the comparison of trends among different intensity ranks of daily precipitation. Figure 13a shows the number of days with precipitation of $\geq 20 \mathrm{~mm}, \geq 50 \mathrm{~mm}$, and $\geq 100 \mathrm{~mm}$. Unlike the $\geq 100 \mathrm{~mm}$ cases, the $\geq 50 \mathrm{~mm}$ cases have only a weak increase $(0.45 \pm 1.02 \% /$ decade $)$, and the $\geq 20 \mathrm{~mm}$ cases show a slight decreasing trend $(-0.40 \pm 0.75 \% /$ decade). Figure $13 \mathrm{~b}$ shows the decadal maximum, annual maximum and the annual tenth values. The annual tenth precipitation has lit- 
Table 3. Linear trends (\%/decade) of heavy daily precipitation indices.

\begin{tabular}{lccccc}
\hline \hline & Whole area & Northern & Eastern & Western & Nansei Islands \\
\hline$\geq 100 \mathrm{~mm}$ days & $2.49 \pm 1.81$ & $3.72 \pm 4.95$ & $1.85 \pm 3.14$ & $3.12 \pm 2.47$ & $1.04 \pm 2.42$ \\
Annual max. & $0.89 \pm 0.72$ & $0.62 \pm 1.12$ & $0.66 \pm 1.23$ & $1.20 \pm 1.06$ & $0.68 \pm 1.58$ \\
Top 100 cases & $2.57 \pm 2.13$ & $2.16 \pm 3.06$ & $1.08 \pm 2.88$ & $4.54 \pm 3.29$ & $0.53 \pm 3.59$ \\
\hline
\end{tabular}

(a) $\geq 100 \mathrm{~mm}$ days

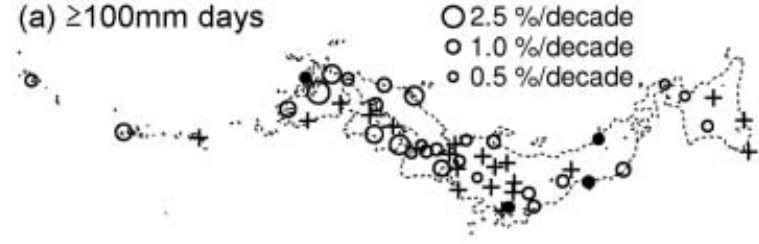

(b) Annual max.

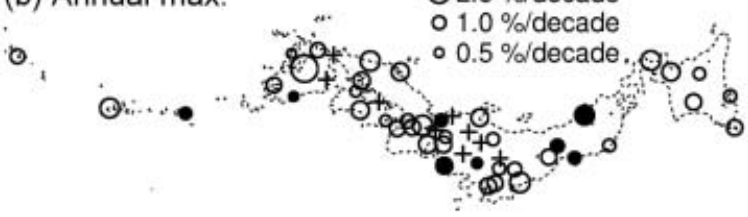

(c) Top 100 cases

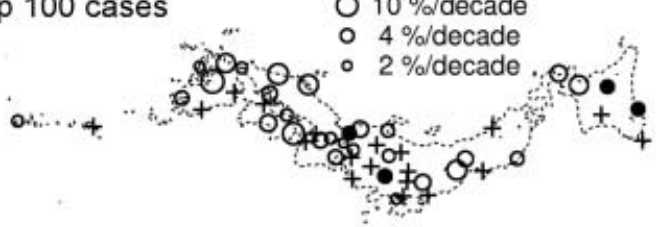

Fig. 12. Distribution of the linear trend of each index. Open and closed circles indicate positive and negative values, respectively. Crosses indicate values less than the smallest value in each legend ( $<5 \% /$ decade for (a), for example).

tle trend $(0.14 \pm 0.58 \%$ /decade), while the decadal maximum shows an increasing trend with almost the same rate as the annual maximum $(1.18 \pm 1.27 \% /$ decade $)$. Figure $13 \mathrm{c}$ shows the top 1000,100 , and 10 cases. The number of top 1000 cases is almost constant with a trend of $0.09 \pm 0.97 \% /$ decade, while the top 10 cases has nearly the same trend as the top 100 cases $(4.10 \pm 4.33 \% /$ decade $)$. Thus increasing trend is characteristic to precipitation having the rarity of the order of once a year, and is not found for less intense precipitation.

Figure 14 shows the time series of annual maximum, and the number of top 100 cases for 1, 5, 11, and 31-day precipitations. A statistically significant trend in the annual maximum

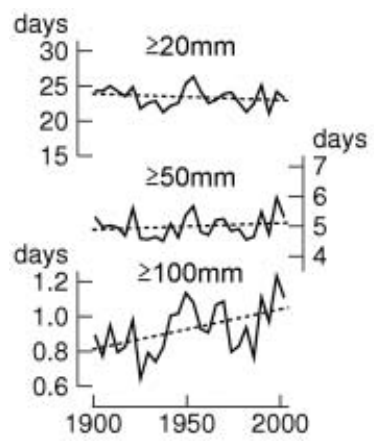

(a)

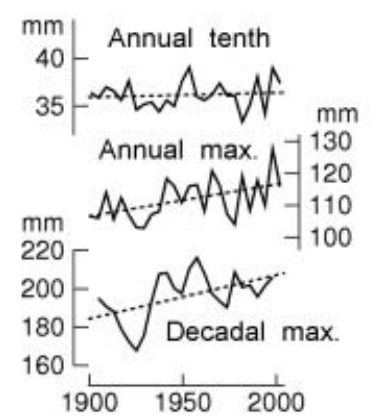

(b)

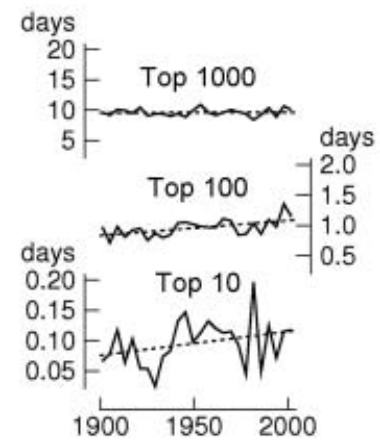

(c)
Fig. 13. Time series of each index in daily precipitation. The graphs of $\geq 100 \mathrm{~mm}$ days, annual maximum precipitation, and the top 100 cases are the same as those shown in Fig. 11.

is found only for daily precipitation, although 5 and 11-day precipitations have a positive trend exceeding 0.5\%/decade. For the top 100 cases, a significant trend is found, not only for daily precipitation, but also for 5-day precipitation $(3.94 \pm 3.75 \% /$ decade $)$. Positive trends exceeding $2 \% /$ decade are found for 11 and 31-day precipitations as well, although statistically insignificant. Thus the increase of heavy precipitation is more conspicuous for a shorter period, although there is some possibility of increase in extreme precipitation of a time scale longer than a week. 


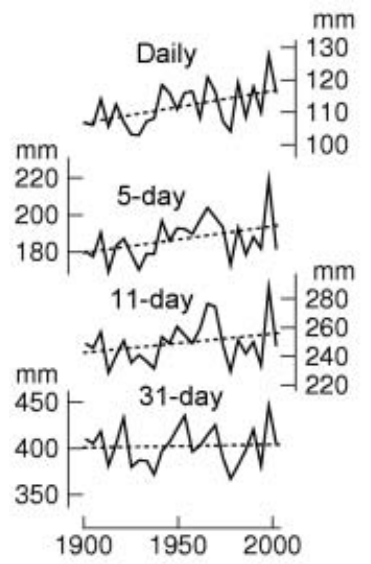

(a) Annual max.

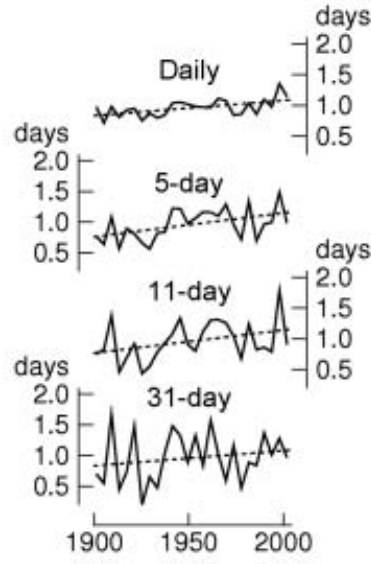

(b) Top 100

Fig. 14. Time series of (a) the annual maximum and (b) the top 100 cases for different time scales.

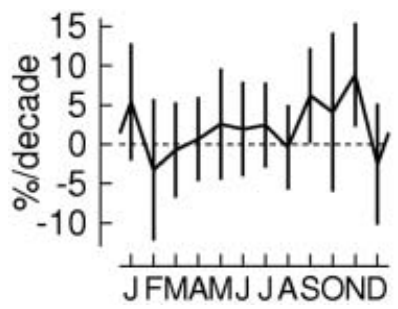

Fig. 15. Linear trend of the frequency of monthly top 10 cases.

As for seasonal dependence, the indices shown in Figs. 12-14 reflect the features in the warm season (Fig. 4). Figure 15 shows the annual variation in the trends of monthly top 10 cases. There are distinct positive trends exceeding 5\%/decade in autumn (September and November), although positive trends exceeding $1 \% /$ decade are found also from May to July, with the annual average of $2.11 \pm 2.00 \% /$ decade. This fact implies that the increase of heavy precipitation is largely contributed by the change in autumn.

\section{Trends in dry weather}

Figure 16a shows the time series of $<1 \mathrm{~mm}$ days for each season and the annual total. There is an increasing trend in all seasons. According to the no evaporation assumption, the trend ranges from $0.5 \% /$ decade in spring to $0.9 \% /$ decade in autumn, with $0.7 \%$ /decade on

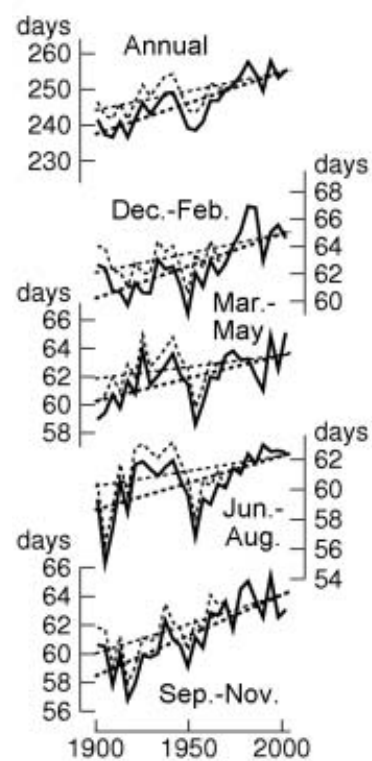

(a) $<1 \mathrm{~mm}$ days

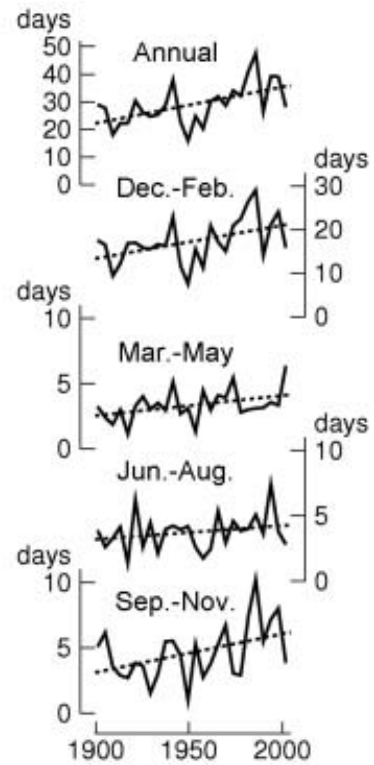

(b) $<30 \mathrm{~mm} /(31$ days)
Fig. 16. Time series of the number of (a) $<1 \mathrm{~mm}$ days and (b) $<30 \mathrm{~mm} /(31$ days) cases. The dashed lines in (a) show the results obtained from the total evaporation assumption.

the annual average. The total evaporation assumption leads to weaker trends, but they are still positive, with sufficient statistical significance (Table 4).

Figure 17 shows the distribution of the trend of $<1 \mathrm{~mm}$ days for each season. The annual values of the trend for the four regions are shown in Table 4. Positive trends are found in all the seasons, over most parts of the country. There are particularly strong trends on the northwestern side of Honshu in winter, indicating the decrease of precipitation frequency in northwesterly monsoon. Trends are relatively weak from central Honshu to Kyushu (western Japan) in spring and summer, while positive trends prevail over the country in autumn.

The increase of $<1 \mathrm{~mm}$ days means a decrease of precipitation days. Indeed, the annual number of $\geq 1 \mathrm{~mm}$ days shows a negative trend of $-1.47 \pm 0.41 \%$ /decade for the no evaporation assumption, and $-0.93 \pm 0.38 \% /$ decade for the total evaporation assumption. For weak precipitation days $(1-5 \mathrm{~mm})$, the trend is as large as $-2.10 \pm 0.40 \% /$ decade, and $-1.15 \pm 0.27 \% /$ decade, respectively. 
Table 4. Linear trends (\%/decade) of dry weather indices.

\begin{tabular}{lrcrrrr}
\hline \hline & Whole area & Northern & \multicolumn{1}{c}{ Eastern } & Western & Nansei Islands & $\begin{array}{r}\text { Whole area } \\
\text { (total evap.) }\end{array}$ \\
\hline$<1$ mm days & $0.71 \pm 0.17$ & $0.62 \pm 0.18$ & $0.71 \pm 0.22$ & $0.65 \pm 0.23$ & $1.54 \pm 0.36$ & $0.43 \pm 0.16$ \\
Lower 5\% & $6.04 \pm 2.78$ & $4.41 \pm 3.05$ & $7.14 \pm 3.69$ & $5.48 \pm 3.81$ & $8.96 \pm 4.76$ & $5.79 \pm 2.78$ \\
Lower $1 \%^{\$}$ & $10.10 \pm 4.27$ & $8.44 \pm 5.06$ & $11.91 \pm 6.05$ & $8.51 \pm 6.02$ & $15.45 \pm 7.45$ & $9.63 \pm 4.28$ \\
\hline
\end{tabular}

$\$$ For 31-day precipitation. See Table 2 for the trend of lower $10 \%$ cases.

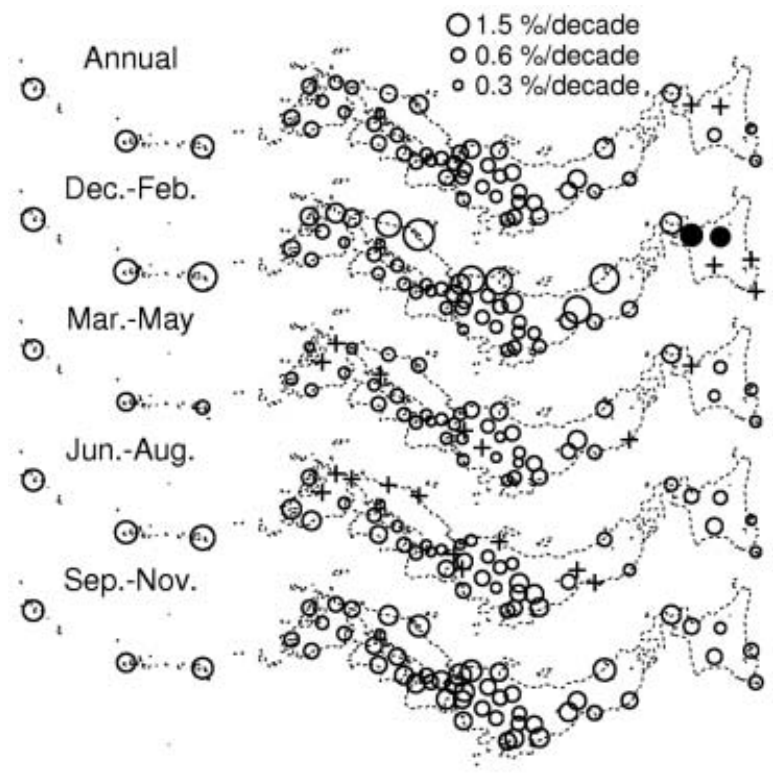

Fig. 17. Distribution of the linear trend of $<1 \mathrm{~mm}$ days. Open and closed circles indicate positive and negative values, respectively. Crosses indicate values less than $0.3 \%$ decade.

Figure $16 \mathrm{~b}$ shows the time series of $<30 \mathrm{~mm} /$ (31 days) cases. There is an increasing trend in all seasons, with an annual average rate of $4.57 \pm 2.82 \% /$ decade. However, there is large seasonal and regional difference in the number of cases, as shown in 2.2 (Figs. $4 \mathrm{~b}$ and $5 \mathrm{c}$ ).

Figure 18a shows the time series of the lower $10 \%, 5 \%$ and $1 \%$ cases of the 31-day precipitation as an index having an equal seasonal and regional weight. On the annual total, the $10 \%$, $5 \%$ and $1 \%$ cases show positive trends of $4.5 \%$ l decade, $6.0 \% /$ decade and $10.1 \% /$ decade, respectively (Tables 2 and 4). Thus the frequency of drier weather has a higher increasing trend. The values of the trend hardly change if the total evaporation assumption is used (Table 4).

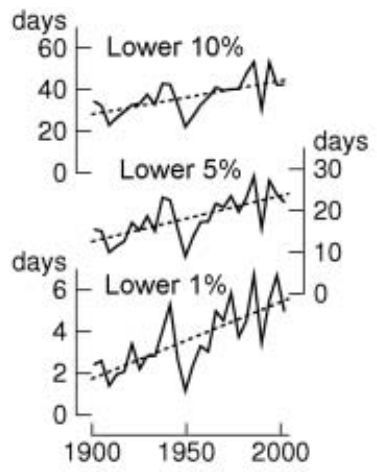

(a)
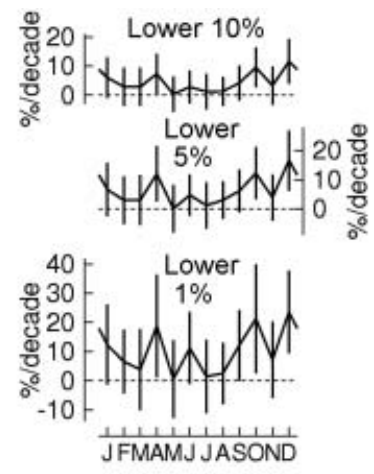

(b)
Fig. 18. (a) Time series of the lower $10 \%$, $5 \%$ and $1 \%$ cases, and (b) the monthly values of the linear trend, for 31-day precipitation.

Figure $18 \mathrm{~b}$ shows the monthly values of the trend. Positive trends are found in all the seasons, with larger values in the cold season than in the warm season. Figure 19 shows the distribution of the trend of the lower $1 \%$ cases. Positive trends prevail in all the seasons, except for Hokkaido in winter, and part of western Japan in spring and summer. The annual trend is statistically significant in all of the four regions (Table 4).

\section{Concluding remarks}

This study has shown the increase of heavy precipitation and the frequency of dry weather in Japan. This result basically agrees with the previous study of Fujibe et al. (2005), who showed the increase of intense precipitation, and decrease of weak precipitation using fourhourly data, although there was some concern about data quality. In this respect, we have confirmed their finding on the basis of quality checked data.

However, there appears to be some difference between the present study and Fujibe et al. 


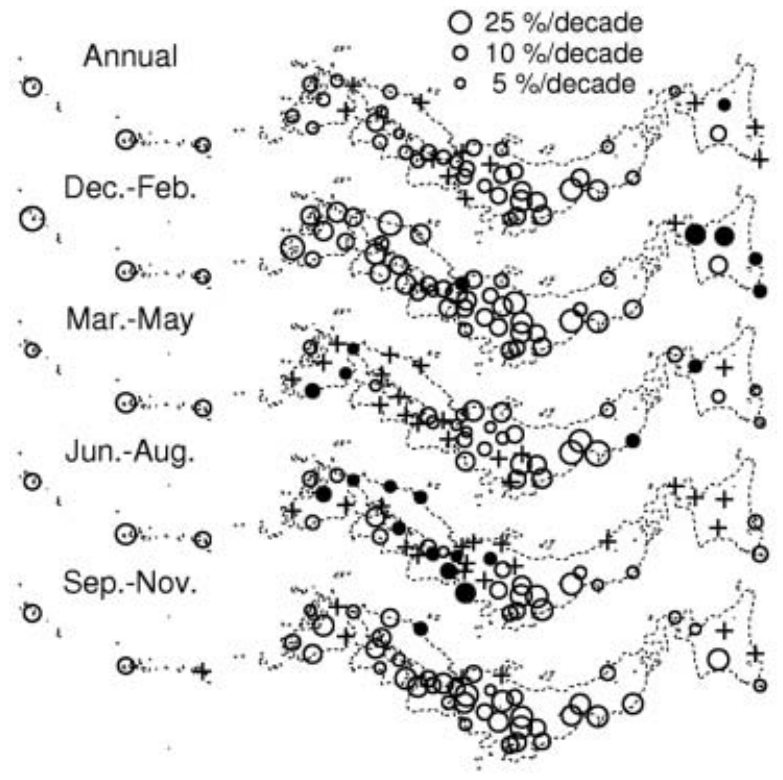

Fig. 19. Distribution of the trend of the lower $1 \%$ cases of 31 -day precipitation. Open and closed circles indicate positive and negative values, respectively. Crosses indicate values less than 5\%/ decade.

(2005). In this result, heavy precipitation has increased mainly in western Japan and in autumn, although weak positive trends are found in most of other regions and seasons. In comparison, regional and seasonal inhomogeniety is less distinct in the result of Fujibe et al. (2005). It is possible that the climatology of long-term changes depends on the time scale of precipitation, which is four-hourly in Fujibe et al. (2005) and daily in ours. It is to be desired to make further analysis on the time scale dependence of long-term changes of heavy precipitation and their climatological features.

As mentioned before, the increase of heavy precipitation has been found in many regions of the world (IPCC 2001; Groisman et al. 2005). The increasing rate of the top 100 daily precipitation events, which account for $0.26 \%$ of the total days, is $2.6 \%$ /decade in our result (Fig. 13c). This value is close to that of the upper $0.1-1 \%$ events in the contiguous United States and former USSR (Groisman et al. 2005). In this respect, our result is analogous to the world-wide increasing tendency of extreme precipitation.
It is to be noted, however, that there is no increasing trend for less intense precipitation, such as $\geq 50 \mathrm{~mm}$ days, and the number of top 1000 cases. This fact indicates that long-term precipitation changes can be strongly dependent on the intensity criterion. The analysis of Groisman et al. (2005) has suggested that heavier precipitation shows a higher trend, while our result implies nearly equal trends between the annual maximum and the decadal maximum precipitations, and between the top 100 and the top 10 cases (Fig. 12). The evaluation of the frequency and long-term change of extremely intense precipitation may require more detailed analysis of rare events.

The increase of no rain days and dry weather, agrees with the changes in eastern China (Zhai et al. 2005), although it may not be a global trend. The high resolution $(100 \mathrm{~km})$ simulation of Kimoto et al. (2005) also shows the increase of both heavy precipitation, and no rain days over Japan and the surrounding region toward the end of the 21st century. In this context, the increase of dry weather in Japan may also be related to global warming, although there is much room for further studies.

\section{References}

Alexander, L.V., X. Zhang, T.C. Peterson, J. Caesar, B. Gleason, A.M.G. Klein Tank, M. Haylock, D. Collins, B. Trewin, F. Rahimzadeh, A. Tagipour, K. Rupa Kumar, J. Revadekar, G. Griffiths, L. Vincent, D.B. Stephenson, J. Burn, E. Aguilar, M. Brunet, M. Taylor, M. New, P. Zhai, M. Rusticucci, and J.L. Vazquez-Aguirre, 2006: Global observed changes in daily climate extremes of temperature and precipitation. J. Geophys. Res., 111, D05109, doi:10.1029/ 2005JD006290.

Brunetti, M., M. Maugeri, F. Monti, and T. Nanni, 2004: Changes in daily precipitation frequency and distribution in Italy over the last 120 years. J. Geophys. Res., 109, D05102, doi:10.1029/2003JD004296.

Dai, A., 1999: Recent changes in the diurnal cycle of precipitation over the United States. Geophys. Res. Lett., 26, 341-344.

Easterling, D.R., G.A. Meehl, C. Parmesan, S. Changnon, T.R. Karl, and L.O. Mearns, 2000: Climate extremes: Observations, modeling and impacts. Science, 289, 2068-2074.

Frich, P., L.V. Alexander, P. Della-Marta, B. Gleason, M. Haylock, A.M.G. Klein Tank, and T. Peterson, 2002: Observed coherent changes in 
climatic extremes during the second half of the twentieth century. Clim. Res., 19, 193212.

Fujibe, F., N. Yamazaki, M. Katsuyama, and K. Kobayashi, 2005: The increasing trend of intense precipitation in Japan based on four-hourly data for a hundred years. SOLA, 1, 41-44, doi: 10.2151/sola.2005-012.

- $\longrightarrow$, and K. Kobayashi, 2006: Long-term changes in the diurnal precipitation cycles in Japan for 106 years (1898-2003). J. Meteor. Soc. Japan, 84, 311-317.

Groisman, P.Y., R.W. Knight, D.R. Easterling, T.R. Karl, G.C. Hegerl, and V.N. Razuvaev, 2005: Trends in intense precipitation in the climate record. J. Climate, 18, 1343-1367.

Haylock, M. and N. Nicholls, 2000: Trends in extreme rainfall indices for an updated high quality data set for Australia, 1910-1998. Int. J. Climatol., 20, 1533-1541.

Hegerl, G.C., F.W. Zwiers, P.A. Stott, and V.V. Kharin, 2004: Detectability of anthropogenic changes in annual temperature and precipitation extremes. J. Climate, 17, 3683-3700.

IPCC, 2001: Climate change 2001: The scientific basis. Contribution of Working Group I to the third Assessment Report of the IPCC [Houghton, J.T. et al. (eds.)]. Cambridge University Press, $881 \mathrm{pp}$.

Iwashima, T. and R. Yamamoto, 1993: A statistical analysis of the extreme events: Long-term trend of heavy daily precipitation. J. Meteor. Soc. Japan, 71, 637-640.

Japan Meteorological Agency, 2005: Climate change monitoring report 2004. Japan Meteorological Agency, 59 pp.

Kajiwara, M., T. Oki, and J. Matsumoto, 2003: Secular change in the frequency of heavy precipitation over Japan for 100 years. Proceedings of the 2003 Spring Meeting of the MSJ, 484 (in Japanese).

Kanae, S., T. Oki, and A. Kashida, 2004: Changes in hourly heavy precipitation at Tokyo from 1890 to 1999. J. Meteor. Soc. Japan, 82, 241-247.

Karl, T.R. and R.W. Knight, 1998: Secular trends of precipitation amount, frequency, and intensity in the United States. Bull. Amer. Meteor. Soc., 79, 231-241.

Kimoto, M., N. Yasutomi, C. Yokoyama, and S. Emori, 2005: Projected changes in precipitation characteristics around Japan under the global warming. SOLA, 1, 85-88, doi: 10.2151/ sola.2005-023.

Kitoh, A., M. Hosaka, Y. Adachi, and Y. Murata, 2004: Changes of precipitation characteristics by global warming simulated by the MRI CGCM. (15th Symposium on Global Change and Climate Variations) AMS, Seattle, January 2004.

New, M., M. Todd, M. Hulme, and P. Jones, 2001: Precipitation measurements and trends in the twentieth century. Int. J. Climatol., 21, 18991922.

Roy, S.S. and R.C. Balling, Jr., 2004: Trends in extreme daily precipitation indices in India. Int. J. Climatol., 24, 457-466.

Semenov, V.A. and L. Bengtsson, 2002: Secular trends in daily precipitation characteristics: Greenhouse gas simulation with a coupled AOGCM. Climate Dyn., 19, 123-140.

Suzuki, H., 2004: Trend in the frequency of heavy rainfall events during the last half century over Japan. Tenki, 51, 805-816 (in Japanese with English abstract).

Takahashi, H., 2003: Secular variation in the occurrence property of summertime daily rainfall amount in and around the Tokyo Metropolitan area. Tenki, 50, 31-41 (in Japanese with English abstract).

Wang, Y. and Zhou, L., 2005: Observed trends in extreme precipitation events in China during 1961-2001 and the associated changes in large-scale circulation. Geophys. Res. Lett., 32, L09707, doi: 10.1029/2005GL022574.

Wehner, M.F., 2004: Predicted twenty-first-century changes in seasonal extreme precipitation events in the parallel climate model. $J$. Climate, 17, 4281-4290.

Zhai, P., X. Zhang, H. Wan, and X. Pan, 2005: Trends in total precipitation and frequency of daily precipitation extremes over China. J. Climate, 18, 1096-1108. 